\title{
PERAN CUSTOMER DELIGHT DALAM MEMODERASI ESTEEM NEEDS TERHADAP NIAT BELI KONSUMEN
}

\author{
Cokorda Istri Agung Vera Nindia Putri ${ }^{1}$ \\ Ida Bagus Sudiksa ${ }^{2}$ \\ ${ }^{1,2}$ Fakultas Ekonomi dan Bisnis Universitas Udayana, Bali, Indonesia \\ e-mail: cokvera_nindya@yahoo.co.id
}

\begin{abstract}
ABSTRAK
Tujuan penelitian ini adalah untuk menganalisis peran customer delight dalam memoderasi esteem needs terhadap niat beli konsumen (studi pada produk Guess). Penelitian ini dilakukan di Provinsi Bali dengan teknik analisis data Moderasi Regresi Analisis (MRA). Ukuran sampel yang didapat dengan menggunakan metode purposive sampling sebanyak 100 responden. Berdasarkan hasil analisis dapat dikemukakan bahwa esteem needs dan customer delight secara langsung berpengaruh positif terhadap niat beli konsumen pada produk Guess. Customer delight terbukti memoderasi hubungan esteem needs terhadap niat beli konsumen pada produk Guess. Saran yang dapat direkomendasikan bagi produsen Guess harus memperhatikan posisi dan pandangan konsumen akan bergunanya suatu produk Guess sehingga menjadi inspirasi dan meningkatkan esteem needs di kalangan masyarakat. Guess harus benar dalam memberikan informasi mengenai kelebihan daripada produk Guess sehingga konsumen merasa nyaman, percaya diri tertarik dan benar-benar Guess sebagai produk yang dicari-cari dan dibutuhkan.
\end{abstract}

Kata kunci: customer delight, esteem needs, niat beli

\begin{abstract}
The purpose of this study is to analyze the role of customer delight in moderating esteem needs to consumer purchase intentions (study on Guess products). This research was conducted in Bali Province with data analysis technique of Moderation Regression Analysis (MRA). Sample size obtained by using purposive sampling method as much as 100 respondents. Based on the results of the analysis can be stated that the esteem needs and customer delight directly affect the consumer's buying intentions on Guess products. Customer delight proved to moderate the relationship of esteem needs to consumers' buying intentions on Guess products. Recommendations that can be recommended for manufacturers Guess should pay attention to the position and views of consumers will use a Guess product to be an inspiration and improve the esteem needs among the community. Guess must be correct in providing information about the advantages over Guess products so that consumers feel comfortable, confident interested and really Guess as a product that is sought and needed.
\end{abstract}

Keywords: Customer Delight, Esteem Needs, Intention to Buy 
Cokorda Istri Agung Vera Nindia Putri, Peran Customer Delight Dalam...

\section{PENDAHULUAN}

Konsekuensi persaingan yang tinggi mengharuskan perusahaan mampu memberikan pelayanan yang baik dalam memuaskan dan mempertahankan konsumen untuk memenangkan persaingan dan tetap mempertahankan eksistensinya (Bayu, 2013). Fashion adalah salah satu perusahaan yang saat ini sebagai industri kreatif di dunia termasuk Indonesia, yang memberikan kontribusi besar bagi pertumbuhan ekonomi Indonesia (Mabrur, 2014). Perusahaan pun dituntut untuk dapat menghadapi persaingan yang semakin ketat. Konsep pemasaran menegaskan perusahaan tidak cukup hanya dengan memproduksi barang dan jasa yang berkualitas sesuai dengan keinginan dan kebutuhan konsumennya dengan harga yang menarik, yang harus dilaksanakan perusahaan adalah menempatkan kepuasan konsumen sebagai tujuan utama dari perusahaan (Meilani et al., 2015).

Tingkat persaingan bisnis yang tinggi membuat perusahaan saling berlomba untuk menguasai persaingan pasar. Imbas dari persaingan yang tinggi tersebut adalah munculnya pilihan produk yang menjadi lebih beragam (Anand et al., 2014). Konsumen menjadi semakin kritis untuk memilih produk yang terbaik bagi mereka, memahami konsumen merupakan elemen yang penting dalam pengembangan strategi pemasaran (Suprihati, 2015). Biasanya strategi pemasaran diarahkan untuk meningkatkan kemungkinan atau frekuensi perilaku konsumen yang dicapai dengan mengembangkan dan menyajikan sistem pemasaran yang diarahkan pada pasar sasaran yang dipilih (Dhevika dan Latasri, 2014). 
Meningkatnya budaya niat beli di Indonesia, terutama di bidang fashion dapat kita lihat dari semakin banyaknya mall di Indonesia dan Kota-kota besar seperti Bali yang tidak kalah hebat dengan mall-mall kelas Dunia. Mall-mall tersebut selalu saja dipenuhi oleh pengunjung, sebagian pengamat Ekonomi mengindikasikan potensi daya beli masyarakat yang besar (Julina dan Desrir, 2014). Melihat potensi ini banyak merek terkenal dan mewah kelas Dunia yang membuka tokonya di Indonesia dan semakin memanjakan sifat konsumerisme masyarakat Indonesia, sebut saja sebagai contoh merek terkenal seperti Guess, Dior, Fossil, Gucci, Balenciaga, Levi's, Armani, Alexader Cristy dan banyak lagi yang ingin meraup keuntungan dari hasil penjualan pada konsumen.

Kebutuhan akan barang mewah dan gaya hidup sebagian besar penduduk di Provinsi Bali sudah menjadi suatu keharusan yang dialami oleh setiap konsumen. Keadaan ini yang membuat setiap produsen produk mewah dan berkelas ikut meramaikan pasar di Bali dengan tujuan mampu meningkatkan pendapatan melalui penjualan produk-produk yang ditawarkan (Hera dan Rafia, 2016). Di tengah krisis global yang menimpa Eropa dan Amerika, penjualan Guess di Indonesia justru bisa menembus angka penjualan tertinggi di seluruh dunia. Brand terbaru Guess yang dibuat dari Swiss dikenal dengan "Guess Collection” yang menawarkan jam tangan lebih membumi dengan harga yang lebih terjangkau tanpa melepaskan kesan mewah. Penawaran yang dilakukan oleh Guess termasuk Guess Collection bisa merebut konsumen di Indonesia khususnya di Bali, dimana anak muda dan para eksekutif menjadi sasaran produk ini yang terkenal dengan kualitasnya yang high-end (beritasatu.com). 
Cokorda Istri Agung Vera Nindia Putri, Peran Customer Delight Dalam...

Indonesia termasuk Bali khususnya di Kota Denpasar dan Kota Badung adalah pasar potensial, "kata Presiden Guess Cindy Livingston dalam peresmian butik baru Guess di area eksklusif Kuta Beachwalk. Cindy Livingston menyatakan kita banyak main di event-event tertentu, dengan berbagai event kita bisa terus memperkenalkan konsep produk dan membantu pemasaran produk Guess di kalangan masyarakat (beritasatu.com). Dalam menghadapi persaingan produk Guess dibandrol dari harga mulai sekitar Rp 950.000 hingga Rp 30.000.000. Harga termahal biasanya merupakan produk signature Guess yang dijual secara terbatas dipasaran sehingga mengesankan barang mewah dan elegan. Selain itu, menurut survei yang dilakukan tentang merek-merek fashion yang terkenal dan menjadi favorit di kalangan pengusaha, wiraswasta, pegawai dan pelajar (mahasiswa) didapatkan hasil bahwa Guess menduduki peringkat pertama dari sekian merek fashion paling terkenal di Bali. Produk Guess dikenal sebagai produk yang memiliki image dengan desain yang baru, ragam warna dan kualitas bagus serta memberikan kesan bergengsi sehingga konsumen tidak segan-segan mengeluarkan banyak uang untuk membelinya.

Melihat permasalahan dari sisi konsumen, kemajuan teknologi dan meluasnya jaringan perusahaan membuat konsumen saat ini memiliki alternatif pilihan yang lebih banyak, tidak hanya yang dihasilkan produsen dalam negeri tetapi juga dari luar negeri (Kenneth dan Oliver, 2012). Trend yang berkembang di suatu negara dengan mudah diakses oleh konsumen dari belahan dunia lain sehingga berpotensi memunculkan permintaan akan suatu produk yang lebih banyak dari masa sebelumnya dan dipermudah lagi dengan adanya perjanjian 
perdagangan antar negara yang membuat konsumen semakin mudah memperoleh produk asing karena dipasarkan juga di negaranya sendiri (Maria, 2015). Trend membanjirnya produk-produk asing di pasar negara lain juga terjadi di Indonesia. Sebagian besar konsumen Indonesia mempersepsikan bahwa produk-produk asing sering memiliki berbagai kelebihan dibanding produk dalam negeri. Secara kualitas kadangkala produk dalam negeri mampu bersaing dengan produk impor, namun kesenangan mengikuti trend terbaru membuat konsumen tetap memburu produk impor (Richard et al., 2016). Penggunaan produk-produk impor ini juga dianggap dapat meningkatkan gengsi sehingga merasa lebih diakui oleh lingkungannya (Vidhya, 2013).

Sri dan Asri (2015) menyatakan bagi konsumen yang orientasi dirinya bertumpu pada prinsip dalam mengambil keputusan membeli akan selalu berdasarkan pada keyakinannya, sehingga keputusannya untuk membeli bukan hanya karena ikut-ikutan atau sekedar untuk mengejar gengsi (esteem needs) dan dapat dikatakan tipe ini lebih rasional. Sandra et al. (2013) menyatakan bagi konsumen yang bertumpu pada emosional, keputusannya dalam membeli di dominasi oleh konsumen lain. Produk-produk branded (bermerek) cenderung menjadi pilihannya dan tidak berpikir lebih lanjut akan manfaatnya karena konsumen merasa mendapatkan rasa adil, nyaman dan penuh gaya dalam menggunakannya (customer delight) dengan penuh percaya diri Norma et al. (2014)

Donald et al. (2015) menyatakan customer delight adalah dimensi people oriented. Customer delight akan terbentuk ketika seseorang merasakan nyaman 
Cokorda Istri Agung Vera Nindia Putri, Peran Customer Delight Dalam...

dengan suatu perusahaan dan mendapatkan perasaan senang. Konsumen yang delight merupakan asset penting bagi perusahaan, peran mereka lebih besar dari sekedar melakukan pembelian produk karena mereka juga menyertakan positif word of mount tentang perusahaan dan juga akan memberikan keuntungan yang besar untuk perusahaan (Gaurav and Divya, 2013). Customer delight sebagai respons emosional dapat memperkuat komitmen pelanggan terhadap penyedia layanan, hal tersebut akan mengarah pada tingkat loyalitas dan niat pembelian konsumen. Konseptualisasi delight sebagai kepuasan ekstrim (Griffin, 2009:75) berasal dari konsep kepuasan, keadaan psikologis yang berasal dari aspek kognitif dan afektif proses konsumsi (Price, 1995:109) dalam Bayu (2013). Telah dikemukakan bahwa transisi dari sekedar memuaskan pelanggan untuk memuaskan mereka telah menjadi tujuan strategis dalam pengalaman konsumsi. Delight adalah emosi yang kompleks yang merupakan campuran dari dua emosi, kombinasi dari sukacita dan kejutan, Plutchik (2002:33) dalam Deviana (2014). Afwan dan Putri (2014) dalam penelitiannya membuktikan customer delight memiliki pengaruh positif pada niat beli konsumen. Baqiyatul (2013) menyatakan niat beli konsumen dapat dibangun secara positif dengan mencitpakan customer delight pada pelanggan. Hal yang sama dinyatakan oleh Alexander et al. (2014) customer delight mampu membangun secara positif minat beli konsumen.

Penggunaan produk-produk impor Guess ini juga dianggap dapat meningkatkan esteem needs konsumen. Consumers esteem needs adalah keinginan konsumen untuk dihargai dan dihormati oleh orang lain ketika berbelanja untuk menggunakan suatu produk. Consumers esteem juga telah diperlakukan sebagai 
hasil penting karena erat kaitannya dengan kesehatan psikologis manusia dan menyebabkan tingkat keyakinannya relatif evaluatif dan kognitif (Deviana, 2014). Terdapat tiga indikator didalam variabel yang digunakan Harmancioglu et al. (2009) dalam (Deviana, 2014) yaitu: selalu ingin dihormati oleh orang lain, mencari kehormatan diri dan mementingkan hubungan dengan orang lain. Deviana (2014) menyatakan dalam penelitiannya esteem needs memicu secara positif niat beli konsumen. Bayu (2013) menyatakan hal yang sama esteem needs memiliki pengaruh pada niat beli konsumen dengan moderasi customer delight secara emosional. Dhevika and Latasri (2014) menyatakan customer delight mampu memoderasi secara positif esteem needs dengan minat beli konsumen.

Guess merupakan merek pakaian fashion dan accessories yang sampai saat ini menjadi incaran para konsumen kalangan menengah atas untuk memiliki segala macam jenis produk yang bermerek Guess. Perusahaan yang didirikan pada tahun 1981 ini memang fokus terhadap dunia fashion baik untuk pria maupun wanita. Guess telah dikenal sebagai produk bermerek tingkat dunia. Koleksi dari Guess ini sangat lengkap mulai dari tas, jam tangan, ikat pinggang, pakaian, accessories dan lainnya (www.gehemniser.com). Banyak masyarakat kalangan menengah atas menyukai produk merek Guess karena nyaman dipakai dan prestisius, merasa sangat percaya diri dan tidak sedikit masyarakat rela berburu ke luar negeri hanya untuk mendapatkan koleksi terbaru dan koleksi limited edition. Harga barang-barang tersebut beragam tergantung dari jenis yang dimininati konsumen. 
Cokorda Istri Agung Vera Nindia Putri, Peran Customer Delight Dalam...

Fenomena ini mengambarkan bahwa kecenderungan konsumen untuk membeli produk fashion karena pemakai berdasarkan respons emosional (customer delight). Konsumen menggunakan status produk sebagai simbol untuk mengkomunikasikan kepada kelompok referensi yang responnya sangat penting bagi pemakai produk (Deviana, 2014). Orang di Indonesia khususnya Bali baik diperkotaan maupun pedesaan termasuk orang yang sangat konsumtif dan esteem needs memberikan peranan sangat besar dalam hal niat beli mereka, apalagi masyarakat di perkotaan yang juga esteem needsnya lebih tinggi, sehingga semakin mahal produk yang dijual semakin banyak yang membeli. Tidak heran Indonesia khususnya Bali menjadi salah satu tujuan utama ekspor produk dari luar Negeri, dikarenakan orang Indonesia termasuk gila akan produk luar Negeri berdasarkan gengsi di masyarakat.

Meningkatnya esteem needs atau harga diri juga rasa gengsi seseorang sewaktu memakai produk Guess, maka pihak produsen Guess harus tetap menjaga kredibilitasnya sebagai produk yang high class dimata konsumen untuk meningkatkan niat beli konsumen, hal ini berarti secara positif esteem needs mampu memberikan pengaruh positif terhadap niat beli konsumen (Deviana, 2014). Esteem needs yang dimiliki konsumen memberikan pengaruh positif signifikan terhadap niat beli konsumen pada produk (Maggie, 2015). Menurut Bayu (2013) menyatakan bahwa niat beli seseorang akan dipengaruhi secara positif signifikan oleh esteem needs yang mereka miliki. Afwan dan Putri (2014) menyatakan variabel niat beli akan dipengaruhi secara positif oleh esteem needs. Meilani et al. (2015) niat beli konsumen secara positif dipengaruhi oleh esteem 
needs. Berdasarkan hasil penelitian yang diuraikan sebelunya tersebut diajukan hipotesis sebagai berikut.

$\mathrm{H}_{1}$ : Esteem needs berpengaruh positif dan signifikan terhadap niat beli konsumen.

Niat beli konsumen sangat dipengaruhi secara positif dan signifikan oleh esteem needs atau harga diri konsumen dengan adanya dukungan dari customer delight yang meliputi rasa nyaman dan percaya diri yang dirasakan pada saat menggunakan produk (Donald et al., 2011). Deviana (2014) membuktikan hal yang sama dengan adanya customer delight mampu memberikan pengaruh positif signifikan memoderasi diantara hubungan esteem needs dengan niat beli konsumen pada produk. Mabrur (2014) mengemukan pengaruh positif esteem needs dengan niat beli konsumen pada produk dibentuk secara moderasi oleh customer delight yang meliputi rasa nyaman dan percaya diri. Sri dan Asri (2015) menyatakan customer delight memiliki peran positif terhadap niat beli konsumen. Richard et al. (2016) membuktikan hal yang sama dimana customer delight memiliki pengaruh positif terhadap niat beli konsumen. Berdasarkan hasil penelitian tersebut, diajukan hipotesis sebagai berikut.

$\mathrm{H}_{2}$ : Customer delight memoderasi pengaruh esteem needs terhadap niat beli konsumen secara positif.

\section{METODE PENELITIAN}

Penelitian ini digolongkan pada penelitian asosiatif. Penelitian asosiatif merupakan penelitian yang bertujuan untuk mengetahui pengaruh ataupun juga hubungan antara dua variabel atau lebih (Sugiyono, 2013). Penelitian dilakukan di mall-mall yang terdapat penjualan Guess. Diantaranya Beachwalk Bali, Sogo Nusa Dua Bali, Dunia Jam, dan Centro. Dari hasil pengamatan di outlet penjualan 
Cokorda Istri Agung Vera Nindia Putri, Peran Customer Delight Dalam...

produk Guess diketahui indikasi kebanyakan konsumen melakukan pembelian berdasarkan keinginan untuk memenuhi gaya hidup yang memberikan rasa percaya diri untuk kesenangan semata. Sebagai obyek dalam penelitian adalah customer delight dalam memoderasi esteem needs terhadap niat beli konsumen pada produk Guess.

Variabel endogen dalam penelitian ini adalah niat beli konsumen. Niat beli merupakan perilaku yang muncul sebagai sikap terhadap suatu produk. Niat beli juga merupakan niat pembelian yang menunjukan keinginan konsumen terhadap suatu produk tertentu.

Variabel yang menjadi moderasi dalam penelitian ini adalah customer delight. Customer delight adalah dimensi people oriented yang akan terbentuk ketika sesorang merasakan nyaman dan senang dengan suatu produk dari perusahaan tertentu dari sekedar melakukan pembelian produk karena mereka juga menyertakan positif word of mount tentang perusahaan dan juga akan memberikan keuntungan yang besar untuk perusahaan Donald et al. (2015).

Variabel eksogen dalam penelitian ini adalah esteem needs. Esteem needs yang dimaksud adalah persepsi orang lain tentang kepercayaan, harga diri konsumen yang dihormati, dikagumi, atau merasa terkenal.

Penelitian ini menggunakan jenis data kualitatif dan data kuantitatif. Data kualitatif merupakan data yang berbentuk kata, kalimat, dan gambar (Sugiyono, 2013:13). Data kualitatif dalam penelitian ini seperti sejarah singkat perusahaan, dan struktur organisasi perusahaan. Data kuantitatif merupakan data yang dapat dihitung dan berupa angka-angka (Sugiyono, 2013:13). Data kuantitatif dalam 
penelitian ini adalah seperti data tanggapan responden terhadap kuisioner yang diberikan, jumlah sampel responden.

Penelitian ini menggunakan sumber data primer dan sekunder. Data primer yaitu data penelitian yang diperoleh langsung dari sumbernya, diamati, dicatat untuk pertama kalinya (Sugiyono, 2013:129). Data primer yang digunakan dalam penelitian ini adalah data yang diperoleh langsung dari responden seputar variabel customer delight, esteem needs terhadap niat beli konsumen pada produk Guess mengenai pendapat pelanggan yang akan dianalisis berdasarkan daftar pertanyaan yang diajukan oleh peneliti dalam kuisioner yang dibagikan. Data sekunder yaitu data yang diperoleh secara tidak langsung oleh peneliti melainkan melalui sumber lainnya (Sugiyono, 2013:129). Data sekunder dalam penelitian ini adalah seperti sejarah perusahaan, struktur organisasi, landasan teoritis, dan buku-buku yang berkaitan dengan pembahasan masalah ini atau dari informasi-informasi lain yang relevan dengan pembahasan yang dibahas.

Populasi adalah wilayah generalisasi yang terdiri atas objek atau subjek yang mempunyai kualitas dan karakteristik tertentu yang telah diterapkan oleh peneliti untuk dipelajari kemudian ditarik kesimpulannya (Sugiyono, 2013:115). Dalam penelitian ini yang menjadi populasi adalah seluruh konsumen yang memiliki niat beli pada produk Guess pada outlet yang ada di mall-mall. Menurut Sugiyono (2013), sampel adalah sebagian dari jumlah dan karakteristik yang dimiliki oleh populasi tersebut. Maka sampel dalam penelitian ini adalah konsumen yang memenuhi kriteria tertentu yang sesuai dengan penelitian niat beli konsumen terhadap produk Guess pada outlet yang ada di mall-mall. Dalam 
Cokorda Istri Agung Vera Nindia Putri, Peran Customer Delight Dalam...

penelitian ini sampel diambil dengan teknik non probability sampling yaitu teknik yang tidak memberi peluang atau kesempatan sama bagi setiap unsur atau anggota populasi untuk dipilih menjadi sampel. Teknik pemilihan sampel menggunakan teknik purposive sampling, yaitu teknik penentuan sampel berdasarkan pertimbangan maupun syarat - syarat tertentu. Untuk memperoleh hasil yang valid dari kuesioner, diperlukan jumlah sampel responden yang diambil untuk mengisi kuesioner dapat ditentukan paling sedikit (5-10) kali jumlah variabel yang diteliti (Sugiyono, 2013). Dalam penelitian ini digunakan 10 indikator sehingga jumlah responden yang digunakan sebagai sampel dalam penelitian ini adalah :

$$
\begin{array}{ll}
\text { Jumlah sampel } & =\text { Jumlah indikator X } 10 \\
& =10 \times 10 \\
& =100 \text { responden }
\end{array}
$$

Penelitian ini menggunakan metode pengumpulan data secara kuesioner dan studi pustaka. Kuesioner merupakan daftar pertanyaan terstruktur yang telah dipersiapkan sebelumnya dan diberikan kepada responden yang telah dipilih dan dipergunakan untuk memperoleh data konsumen atau responden. Melalui kuisioner maka akan diperoleh informasi yang relevan dengan tujuan survey dan dapat memperoleh informasi seakurat mungkin. Peneliti memperoleh data yang berkaitan dengan masalah yang sedang diteliti melalui buku, jurnal, skripsi, tesis, internet, dan perangkat lain yang berkaitan dengan judul penelitian.

Analisis faktor konfirmatori adalah salah satu metode analisis multivariat yang dapat digunakan untuk menkonfirmasi apakah model pengukuran yang dibangun sesuai dengan yang dihipotesiskan (Ghozali, 2011). Analisis faktor konfirmatori digunakan untuk menguji apakah indikator betul-betul merupakan 
indikator suatu variabel. Analisis ini akan mengelompokkan masing-masing indikator ke dalam beberapa faktor. Jika tiap-tiap indikator merupakan indikator suatu variabel, maka dengan sendirinya akan mengelompok menjadi satu dengan faktor loading yang tinggi. Suatu indikator dikatakan valid merefleksikan sebuah faktor jika kriteria berikut terpenuhi.

Tabel 1.

Kriteria Ketepatan Analisis Faktor

\begin{tabular}{ll}
\hline \multicolumn{1}{c}{ Uraian } & Kriteria \\
\hline Bartlett Test & Sig $<\mathbf{0 , 0 5}$ \\
KMO & Value $\geq \mathbf{0 , 5}$ \\
MSA & Value $\geq \mathbf{0 , 5}$ \\
PCA & Value $\geq \mathbf{0 , 5}$ \\
Loading Faktor & Value $\geq \mathbf{0 , 5}$ \\
\hline
\end{tabular}

Sumber: Ferdinand 2002, Ghozali 2011

MRA merupakan aplikasi khusus regresi linear berganda, dimana dalam persamaan regresinya mengandung unsur interaksi (perkalian dua atau lebih variabel independen). Uji analisis koefisien regresi akan menggunakan uji Moderated Regression Analysis (MRA). Memilih MRA dalam penelitian ini menjelaskan variabel pemoderasi dalam memperkuat atau memperlemah hubungan antara variabel independen dan dependen. Perhitungan statistik akan dianggap signifikan apabila nilai ujinya berada dalam daerah kritis (daerah dimana $\mathrm{H}_{0}$ ditolak). Sebaliknya, apabila nilai uji berada di luar daerah kritis $\left(\mathrm{H}_{0}\right.$ diterima), maka perhitungan statistiknya tidak signifikan. Model regresi dalam penelitian ini ditunjukan dengan persamaan sebagai berikut.

$$
Y=\alpha+\beta_{1} X_{1}+\beta_{2} X_{2}+\beta_{3} Z+\beta_{4} X_{1} Z+\beta_{5} X_{2} Z+e
$$

Keterangan :

$\mathrm{Y}=$ Niat beli konsumen

$\alpha \quad=$ Konstanta

$\beta_{1}-\beta_{5}=$ Koefisien

$\mathrm{X}_{1} \quad=$ Esteem needs 
Cokorda Istri Agung Vera Nindia Putri, Peran Customer Delight Dalam...

$$
\begin{array}{ll}
\mathrm{Z} & =\text { Customer delight } \\
e & =\text { Error }
\end{array}
$$

\section{HASIL DAN PEMBAHASAN}

Sebuah instrumen dikatakan valid jika mampu mengukur apa yang seharusnya diukur, dan dapat mengungkap data dari variabel yang diteliti secara tepat. Syarat minimum untuk dianggap memenuhi syarat adalah kalau $r=0,3$ ”. Jadi kalau korelasi antara butir skor dengan skor total kurang dari 0,3 maka butir dalam instrumen tersebut dinyatakan tidak valid. Adapun hasil uji validitas dapat dilihat pada Tabel 2 berikut.

Tabel 2.

Hasil Uji Validitas

\begin{tabular}{cllrc}
\hline No & Variabel & Indikator & Korelasi & Keterangan \\
\hline 1 & Esteem Needs $(\mathrm{X})$ & $\mathrm{X} 1.1$ & 0,748 & Valid \\
& & $\mathrm{X} 1.2$ & 0,782 & Valid \\
& & $\mathrm{X} 1.3$ & 0,772 & Valid \\
& & $\mathrm{X} 1.4$ & 0,800 & Valid \\
\hline 2 & Customer Delight $(\mathrm{Z})$ & $\mathrm{X} 1.1$ & 0,787 & Valid \\
& & $\mathrm{X} 1.2$ & 0,852 & Valid \\
& & $\mathrm{X} 1.3$ & 0,881 & Valid \\
\hline \multirow{2}{*}{3} & \multirow{2}{*}{ Niat Beli (Y) } & $\mathrm{Y} .1$ & 0,780 & Valid \\
& & $\mathrm{Y} .2$ & 0,707 & Valid \\
& & $\mathrm{Y} .3$ & 0,790 & Valid \\
\hline
\end{tabular}

Sumber: data primer diolah, 2017

Tabel 2 dapat dijelaskan bahwa masih-masing indikator variabel memiliki nilai person correlation lebih besar dari 0,30 , maka ini berarti indikator/pertanyaan yang digunakan layak digunakan untuk mengukur apa yang seharusnya diukur, dan dapat mengungkap data dari variabel yang diteliti secara tepat.

Reliabilitas merupakan suatu angka indeks yang menunjukan kosistensi suatu alat ukur dalam mengukur gejala yang sama. Uji reabilitas mampu menunjukan sejauh mana instrument dapat dipercaya dan diharapkan. Nilai suatu 
instrumen dikatakan reliabel bila nilai Alpha Cronbach $\geq 0,6$. Adapun hasil uji reliabilitas dapat dilihat pada Tabel 3 berikut.

Tabel 3.

Hasil Uji Reliabilias

\begin{tabular}{|c|c|c|c|}
\hline No & Variabel & $\begin{array}{c}\text { Cronbach's } \\
\text { Alpha }\end{array}$ & Keterangan \\
\hline 1 & Esteem Needs $(\mathrm{X})$ & 0,778 & Reliabel \\
\hline 2 & Customer Delight (Z) & 0,792 & Reliabel \\
\hline 3 & Niat Beli (Y) & 0,634 & Reliabel \\
\hline
\end{tabular}

Sumber: data primer diolah, 2017

Tabel 3 di atas dijelaskan bahwa nilai Cronbach's Alpha untuk masingmasing variabel $>0,6$, ini berarti alat ukur tersebut akan memberikan hasil yang konsisten apabila alat ukur tesebut digunakan kembali untuk meneliti obyek yang sama.

Tabel 4.

Hasil Penilaian Responden atas Variabel Esteem Needs

\begin{tabular}{|c|c|c|c|c|c|c|c|c|}
\hline \multirow{2}{*}{ No } & \multirow{2}{*}{ Pernyataan } & \multicolumn{5}{|c|}{ Jawaban } & \multirow{2}{*}{$\begin{array}{l}\text { Rata-rata } \\
\text { Skor }\end{array}$} & \multirow{2}{*}{$\begin{array}{l}\text { Kategori } \\
\text { Penilaian }\end{array}$} \\
\hline & & STS & TS & $\mathbf{N}$ & $\mathbf{S}$ & SS & & \\
\hline 1 & $\begin{array}{l}\text { Persepsi orang lain merupakan } \\
\text { penilaian pada produk Guess } \\
\text { yang saya beli. }\end{array}$ & 0 & 10 & 19 & 42 & 29 & 3,90 & Baik \\
\hline 2 & $\begin{array}{l}\text { Saya menghargai pendapat } \\
\text { orang mengenai produk Guess. }\end{array}$ & 0 & 12 & 22 & 31 & 35 & 3,89 & Baik \\
\hline 3 & $\begin{array}{l}\text { Saya menghormati kejujuran } \\
\text { serta inspirasi pandangan orang } \\
\text { mengenai produk Guess yang } \\
\text { saya beli }\end{array}$ & 0 & 14 & 30 & 22 & 34 & 3,76 & Baik \\
\hline 4 & $\begin{array}{l}\text { Saya mengagumi pandangan } \\
\text { orang lain produk Guess sebagai } \\
\text { panutan mereka dalam bergaya }\end{array}$ & 0 & 25 & 22 & 24 & 29 & 3,57 & Baik \\
\hline & Variabel este & needs & & & & & 3,78 & Baik \\
\hline
\end{tabular}

Sumber: data primer diolah, 2017

Tabel 4 menjelaskan persepsi responden mengenai variabel esteem needs dapat dilihat secara keseluruhan memiliki nilai total rata-rata jawaban responden sebesar 3,78 yang masuk dalam kategori baik. Pernyataan pertama yaitu "persepsi orang lain merupakan penilaian pada produk Guess yang saya beli” dengan skor nilai jawaban tertinggi sebesar 3,90 dan skor terendah sebesar 3,57 berada pada 
Cokorda Istri Agung Vera Nindia Putri, Peran Customer Delight Dalam...

pernyataan ke empat yaitu "saya mengagumi pandangan orang lain yang menjadikan produk Guess sebagai panutan mereka dalam bergaya". Maka dari itu produsen produk Guess harus memperhatikan posisi dan pandangan konsumen akan bergunanya suatu produk Guess sehingga menjadi inspirasi dan meningkatkan esteem needs di kalangan masyarakat.

Tabel 5.

Hasil Penilaian Responden atas Variabel Customer Delight

\begin{tabular}{|c|c|c|c|c|c|c|c|c|}
\hline \multirow{2}{*}{ No } & \multirow{2}{*}{ Pernyataan } & \multicolumn{5}{|c|}{ Jawaban } & \multirow{2}{*}{$\begin{array}{c}\text { Rata-rata } \\
\text { Skor }\end{array}$} & \multirow{2}{*}{$\begin{array}{l}\text { Kategori } \\
\text { Penilaian }\end{array}$} \\
\hline & & STS & TS & $\mathbf{N}$ & $\mathbf{S}$ & SS & & \\
\hline 1 & $\begin{array}{l}\text { Saya memperoleh informasi } \\
\text { mengenai produk Guess } \\
\text { secara akurat. }\end{array}$ & 0 & 5 & 32 & 39 & 24 & 3,82 & Baik \\
\hline 2 & $\begin{array}{l}\text { Staf Guess menunjukkan } \\
\text { sikap perhatian sehingga } \\
\text { terlihat tertarik untuk } \\
\text { menolong saya dalam } \\
\text { melakukan pembelian }\end{array}$ & 0 & 5 & 23 & 41 & 31 & 3,98 & Baik \\
\hline 3 & $\begin{array}{l}\text { Sebagai konsumen, saya } \\
\text { mendapat sesuatu lebih dari } \\
\text { yang diharapkan pada } \\
\text { produk Guess. }\end{array}$ & 0 & 10 & 23 & 45 & 22 & 3,79 & Baik \\
\hline \multicolumn{7}{|c|}{ Variabel customer delight } & 3,86 & Baik \\
\hline
\end{tabular}

Sumber: data primer diolah, 2017

Tabel 5 menjelaskan persepsi responden mengenai variabel customer delight dapat dilihat secara keseluruhan memiliki nilai total rata-rata jawaban responden sebesar 3,86 yang masuk dalam kategori baik. Pernyataan kedua yaitu "Staf Guess menunjukkan sikap perhatian sehingga terlihat tertarik untuk menolong saya dalam melakukan pembelian" memiliki skor nilai jawaban tertinggi sebesar 3,98 dan skor terendah sebesar 3,79 berada pada pernyataan ke tiga "sebagai konsumen, saya mendapat sesuatu yang lebih dari yang diharapkan pada produk Guess". Maka dari itu produsen Guess di Provinsi Bali harus memberikan informasi mengenai kelebihan daripada produk Guess sehingga konsumen merasa tertarik dan benar-benar Guess sebagai produk yang dicari-cari dan dibutuhkan. 
Tabel 6.

Hasil Penilaian Responden atas Variabel Niat Beli

\begin{tabular}{|c|c|c|c|c|c|c|c|c|}
\hline \multirow{2}{*}{ No } & \multirow{2}{*}{ Pernyataan } & \multicolumn{5}{|c|}{ Jawaban } & \multirow{2}{*}{$\begin{array}{c}\text { Rata-rata } \\
\text { Skor }\end{array}$} & \multirow{2}{*}{$\begin{array}{l}\text { Kategori } \\
\text { Penilaian }\end{array}$} \\
\hline & & STS & TS & $\mathbf{N}$ & $\mathbf{S}$ & SS & & \\
\hline 1 & $\begin{array}{l}\text { Saya memiliki ketertarikan serta } \\
\text { melakukan peninjauan kembali } \\
\text { terhadap produk Guess yang } \\
\text { akan dibeli }\end{array}$ & 0 & 4 & 36 & 38 & 22 & 3,78 & Baik \\
\hline 2 & $\begin{array}{l}\text { Saya memiliki keinginan dalam } \\
\text { melakukan pembelian terhadap } \\
\text { produk Guess }\end{array}$ & 0 & 14 & 37 & 32 & 17 & 3,52 & Baik \\
\hline 3 & $\begin{array}{l}\text { Saya memutuskan dengan cepat } \\
\text { untukmelakukan pembelian } \\
\text { produk Guess }\end{array}$ & 0 & 11 & 32 & 34 & 23 & 3,69 & Baik \\
\hline \multicolumn{7}{|c|}{ Variabel niat beli } & 3,66 & Baik \\
\hline
\end{tabular}

Sumber: data primer diolah, 2017

Tabel 6 menjelaskan persepsi responden mengenai variabel niat beli dapat dilihat secara keseluruhan memiliki nilai total rata-rata jawaban responden sebesar 3,66 yang masuk dalam kategori baik. Pernyataan pertama yaitu "saya memiliki ketertarikan serta melakukan peninjauan kembali terhadap produk Guess yang akan dibeli" dengan skor nilai jawaban tertinggi sebesar 3,78 dan skor terendah sebesar 3,53 berada pada pernyataan kedua yaitu "saya memiliki keinginan dalam melakukan pembelian terhadap produk Guess". Maka dari itu produsen produk Guess harus memperhatikan pertimbangan-pertimbangan yang dijadikan alasan untuk membeli oleh konsumen, seperti harga, kualitas dari produk yang harus benar-benar mampu bersaing dengan produk pesaing sehingga konsumen memiliki keinginan untuk membeli produk Guess.

Tabel 7.

Koefisien Korelation Matriks Variabel

\begin{tabular}{clcc}
\hline No & \multicolumn{1}{c}{ Variabel } & Chi-square & Sig \\
\hline 1 & Esteem Needs $(\mathrm{X})$ & 108,417 & 0,000 \\
2 & Customer Delight $(\mathrm{Z})$ & 66,849 & 0,000 \\
3 & Niat Beli $(\mathrm{Y})$ & 56,116 & 0,000 \\
\hline
\end{tabular}

Sumber: data primer diolah, 2017 
Cokorda Istri Agung Vera Nindia Putri, Peran Customer Delight Dalam...

Tabel 7 menunjukkan bahwa nilai Chi-square untuk masing-masing variabel dengan nilai signifikansi dibawah 0,05 , maka ini berarti masing-masing item pada instrument memiliki nilai korelasi yang kuat sehingga layak dipergunakan dalam analisis faktor.

Tabel 8.

Uji Kaiser Mayer Olkin (KMO)

\begin{tabular}{clcc}
\hline No & \multicolumn{1}{c}{ Variabel } & KMO & Ket. \\
\hline 1 & Esteem Needs $(\mathrm{X})$ & 0,783 & Valid \\
2 & Customer Delight $(\mathrm{Z})$ & 0,600 & Valid \\
3 & Niat Beli (Y) & 0,672 & Valid \\
\hline
\end{tabular}

Sumber: data primer diolah, 2017

Berdasarkan Tabel 8 menunjukkan bahwa nilai Kaiser Mayer Olkin (KMO) untuk masing-masing variabel lebih besar dari 0,5. Ini berarti masing-masing variabel memiliki kecukupan sampel untuk melakukan analisis faktor.

Tabel 9.

Analisis Measure of Sampling Adequacy (MSA)

\begin{tabular}{clcc}
\hline No & Variabel & Item Pernyataan & Nilai MSA \\
\hline 1 & Esteem Needs $(\mathrm{X})$ & $\mathrm{X} 1.1$ & 0,762 \\
& & $\mathrm{X} 1.2$ & 0,811 \\
& & $\mathrm{X} 1.3$ & 0,810 \\
& & $\mathrm{X} 1.4$ & 0,760 \\
\hline 2 & Customer Delight $(\mathrm{Z})$ & $\mathrm{Z} .1$ & 0,645 \\
& & $\mathrm{Z} .2$ & 0,615 \\
& & $\mathrm{Z} .3$ & 0,566 \\
\hline 3 & Niat Beli (Y) & $\mathrm{Y} .1$ & 0,652 \\
& & $\mathrm{Y} .2$ & 0,659 \\
& & $\mathrm{Y} .3$ & 0,715 \\
\hline
\end{tabular}

Sumber: data primer diolah, 2017

Tabel 9 menunjukkan nilai MSA untuk masing-masing indikator variabel lebih besar dari 0,5, maka ini berarti model yang digunakan layak dipergunakan dalam model analisis faktor. 
Tabel 10.

Nilai Eigen Value

\begin{tabular}{clcc}
\hline No & \multicolumn{1}{c}{ Variabel } & $\begin{array}{c}\text { Eigen } \\
\text { Value }\end{array}$ & $\begin{array}{c}\text { Cumulative } \\
\text { Variance (persent) }\end{array}$ \\
\hline 1 & Esteem Needs $(\mathrm{X})$ & 2,455 & 61,376 \\
2 & Customer Delight $(\mathrm{Z})$ & 1,923 & 64,114 \\
3 & Niat Beli (Y) & 1,911 & 63,689 \\
\hline
\end{tabular}

Sumber: data primer diolah, 2017

Berdasarkan Tabel 10 menunjukkan nilai eigen value dan masing-masing variabel lebih besar dari 1, dan nilai percentage of variance lebih besar dari 5 persen, maka ini berarti masing-masing variabel yaitu esteem needs (X) dan customer delight $(\mathrm{Z})$ merupakan variabel yang berpengaruh terhadap niat beli konsumen (Y), sehingga layak dipergunakan dalam model.

Tabel 11.

Nilai Loading Faktor

\begin{tabular}{cccc}
\hline Variabel & Indikator & Loading Faktor & Ket. \\
\hline \multirow{4}{*}{ Esteem Needs $(\mathrm{X})$} & $\mathrm{X}_{.1}$ & 0,805 & Valid \\
& $\mathrm{X}_{.2}$ & 0,760 & Valid \\
& $\mathrm{X}_{.3}$ & 0,759 & Valid \\
& $\mathrm{X}_{.4}$ & 0,808 & Valid \\
\hline \multirow{3}{*}{ Customer Delight $(\mathrm{Z})$} & $\mathrm{Z}_{.1}$ & 0,737 & Valid \\
& $\mathrm{Z}_{.2}$ & 0,775 & Valid \\
& $\mathrm{Z}_{.3}$ & 0,883 & Valid \\
\hline \multirow{3}{*}{ Niat Beli (Y) } & $\mathrm{Y}_{1}$ & 0,818 & Valid \\
& $\mathrm{Y}_{2}$ & 0,810 & Valid \\
& $\mathrm{Y}_{3}$ & 0,765 & Valid \\
\hline
\end{tabular}

Sumber: data primer diolah, 2017

Tabel 11 menunjukkan bahwa nilai rotasi instrumen untuk masing-masing variabel lebih besar dari 0,4 maka ini berarti seluruh instrument dari masingmasing variabel telah memenuhi syarat dan menunjukkan korelasi yang kuat.

Teknik analisis data yang diterapkan dalam penelitian ini dilakukan secara kuantitatif dengan penekanan data yang bersumber dari data primer, yang mana data tersebut akan diolah kemudian dianalisis. Teknik perhitungan dan analisis data menggunakan Moderating Regression Analysis. Moderating Regression 
Cokorda Istri Agung Vera Nindia Putri, Peran Customer Delight Dalam...

Analysis dinyatakan dalam bentuk regresi berganda dengan persamaan mirip regressi polynomial yang menggambarkan pengaruh dengan menggunakan Uji Nilai Selisih Mutlak untuk mengetahui peran customer delight dalam memoderasi esteem needs terhadap niat beli konsumen pada produk Guess dengan bantuan program Statistical Package of Social Science (SPSS). Hasil pengujian disajikan dalam hasil uji nilai selisih mutlak pada Tabel 12 berikut ini.

Tabel 12.

Hasil Pelaporan Analisis MRA

\begin{tabular}{|c|c|c|c|c|c|}
\hline \multirow[t]{2}{*}{ Variabel } & \multicolumn{2}{|c|}{ Koefisien Regresi } & \multirow{2}{*}{$\begin{array}{c}\begin{array}{c}\text { Standardized } \\
\text { Coefficients }\end{array} \\
\text { Beta } \\
\end{array}$} & \multirow[t]{2}{*}{$\mathbf{t}$} & \multirow[t]{2}{*}{ Sig } \\
\hline & $\mathbf{B}$ & Std. error & & & \\
\hline (constant) & $-0,097$ & 0,069 & & $-1,403$ & 0,164 \\
\hline Esteem needs & 0,213 & 0,074 & 0,213 & 2,863 & 0,005 \\
\hline Customer delight & 0,751 & 0,071 & 0,731 & 10,269 & 0,000 \\
\hline $\begin{array}{l}\text { Esteem needs- } \\
\text { customer delight }\end{array}$ & 0,149 & 0,068 & 0,127 & 2,179 & 0,032 \\
\hline \multicolumn{2}{|c|}{ Dependen variabel } & \multicolumn{2}{|c|}{ : Niat beli konsumen } & & \\
\hline \multicolumn{2}{|c|}{ F Statistik } & : 84,98 & & & \\
\hline \multicolumn{2}{|l|}{ Sig F } & : 0.000 & & & \\
\hline \multicolumn{2}{|l|}{$\mathbf{R}^{2}$} & : $\mathbf{0 , 7 2 6}$ & & & \\
\hline \multicolumn{2}{|c|}{ Adjusted R ${ }^{2}$} & : $\quad 0,718$ & & & \\
\hline
\end{tabular}

Sumber : data primer diolah, 2017

Hasil uji statistik F pada Tabel 12, menunjukan hasil nilai siginifikansi sebesar 0,000 yang lebih kecil dari tingkat $\alpha=0,05$. Hal ini berarti variabel esteem needs, customer delight secara bersamaan berpengaruh signifikan terhadap niat beli konsumen pada produk Guess. Hal ini mengindikasikan bahwa model yang digunakan dalam penelitian ini layak dipergunakan.

Pengujian koefisien determinasi $\left(\mathrm{R}^{2}\right)$ dilakukan untuk mengetahui seberapa besar variasi variabel dependent akan mampu dijelaskan oleh variabel independennya, sedangkan sisanya dijelaskan oleh sebab-sebab variabel lain di luar model (Ghozali, 2011:97). Berdasarkan Tabel 12 menunjukan bahwa nilai adjusted $\mathrm{R}$ square model 0,729 atau sebesar $72,9 \%$ artinya sebesar $72,9 \%$ variasi 
atau perubahan niat beli konsumen dapat dijelaskan oleh variasi variabel dalam model tersebut yaitu esteem needs dengan customer delight.

Hasil perhitungan uji t dapat dilihat pada Tabel 12. Dari tabel tersebut diketahui bahwa nilai koefisien regresi $\mathrm{X}_{1}$ adalah sebesar 0,213 dengan tingkat signifikansi sebesar 0,005 lebih kecil dibandingkan dengan taraf nyata $\alpha=0,05$. Hal ini menunjukan bahwa esteem needs berpengaruh positif dan signifikan terhadap niat beli konsumen pada produk Guess. Semakin tinggi esteem needs maka niat beli juga semakin meningkat. Hipotesis yang menyatakan bahwa esteem needs berpengaruh positif dan signifikan terhadap niat beli konsumen diterima.

Hasil analisis data esteem needs memberikan pengaruh positif terhadap niat beli konsumen, dengan nilai pengaruh variabel esteem needs besaran t hitung sebesar 2,863 dan tingkat signifikansi $0,005<0,05$ artinya terlihat adanya esteem needs yang tinggi pada diri konsumen memberikan pengaruh positif terhadap niat beli konsumen pada produk. Hasil penelitian ini searah dengan pernyataan Deviana (2014) yang membuktikan bahwa niat beli konsumen akan terwujud apabila esteem needs yang dimilikinya dapat terpenuhi. Esteem needs yang dimiliki konsumen memberikan pengaruh positif signifikan terhadap niat beli konsumen pada produk (Maggie, 2015). Afwan dan Putri (2014) membuktikan yang sama variabel niat beli akan dipengaruhi secara positif oleh esteem needs. Meilani et al. (2015) niat beli konsumen secara positif dipengaruhi oleh esteem needs. Niat beli konsumen sangat dipengaruhi secara positif dan signifikan oleh esteem needs yang dimiliki konsumen (Bayu, 2013). 
Cokorda Istri Agung Vera Nindia Putri, Peran Customer Delight Dalam...

Hasil perhitungan uji t dapat dilihat pada Tabel 12. Dari tabel tersebut diketahui bahwa nilai koefisien regresi $\mathrm{X}_{2}$ adalah sebesar 0,731 dengan tingkat signifikansi sebesar 0,000 lebih kecil dibandingkan dengan taraf nyata $\alpha=0,05$. Hal ini menunjukan bahwa customer delight berpengaruh positif dan signifikan terhadap niat beli konsumen pada produk Guess, artinya semakin tinggi customer delight maka niat beli semakin meningkat. Hipotesis yang menyatakan bahwa customer delight berpengaruh positif dan signifikan terhadap niat beli konsumen diterima.

Berdasarkan hasil analisis data diketahui bahwa customer delight terhadap niat beli konsumen berpengaruh signifikan positif, dengan nilai pengaruh variabel Customer Delight besaran t hitung sebesar 10,269 dan tingkat signifikansi 0,000< 0,05. Hal ini mengandung arti bahwa semakin tinggi kebutuhan akan rasa nyaman dan percaya diri atau customer delight seorang konsumen berakibat positif pada niat beli konsumen untuk membeli produk Guess. Hasil penelitian ini mendukung pernyataan Donald et al. (2011) dimana niat beli konsumen sangat dipengaruhi secara positif dan signifikan oleh customer delight yang meliputi rasa nyaman dan percaya diri yang dirasakan pada saat menggunakan produk. Deviana (2014) membuktikan hal yang sama dengan adanya customer delight mampu memberikan pengaruh positif signifikan terhadap niat beli konsumen pada produk.

Hasil perhitungan uji t dapat dilihat pada Tabel 12. diketahui bahwa nilai koefisien regresi $\left|\mathrm{ZX}_{1}-\mathrm{ZX}_{3}\right|$ atau variabel esteem needs dan customer delight adalah sebesar 0,127 dengan tingkat signifikansi sebesar 0,032 lebih kecil dibandingkan dengan taraf nyata $\alpha=0,05$. Hal ini menunjukan bahwa customer 
delight berperan sebagai variabel yang memoderasi hubungan antara esteem needs dengan niat beli konsumen pada produk Guess. Hipotesis yang menyatakan customer delight memoderasi pengaruh esteem needs terhadap niat beli konsumen secara positif diterima.

Berdasarkan hasil analisis data diketahui bahwa customer delight dapat memperkuat pengaruh esteem needs terhadap niat beli konsumen secara positif, dengan nilai pengaruh variabel costomer delight memoderasi esteem needs terhadap niat beli besaran t hitung sebesar 2,179 dan tingkat signifikansi 0,032 < 0,05. Hal ini mengandung arti bahwa semakin tinggi customer delight seorang konsumen berakibat positif dengan esteem needs konsumen sehingga meningkatkan niat beli konsumen untuk membeli produk Guess. Hasil penelitian ini mendukung pernyataan Donald et al. (2011) dimana niat beli konsumen sangat dipengaruhi secara positif dan signifikan oleh esteem needs atau harga diri konsumen dengan adanya dukungan dari customer delight yang meliputi rasa nyaman dan percaya diri yang dirasakan pada saat menggunakan produk. Mabrur (2014) mengemukan pengaruh positif esteem needs dengan niat beli konsumen pada produk dibentuk secara moderasi oleh customer delight yang meliputi rasa nyaman dan percaya diri. Sri dan Asri (2015) menyatakan customer delight memiliki peran positif terhadap niat beli konsumen. Richard et al. (2016) membuktikan hal yang sama dimana customer delight memiliki pengaruh positif terhadap niat beli konsumen. Deviana (2014) membuktikan hal yang sama dengan adanya customer delight mampu memberikan pengaruh positif signifikan 
Cokorda Istri Agung Vera Nindia Putri, Peran Customer Delight Dalam...

memoderasi diantara hubungan esteem needs dengan niat beli konsumen pada produk.

\section{SIMPULAN DAN SARAN}

Berdasarkan hasil penelitian di atas maka dapat ditarik kesimpulan bahwa Esteem needs berpengaruh positif dan signifikan terhadap niat beli konsumen pada produk Guess. Customer delight berpengaruh positif dan signifikan terhadap niat beli konsumen pada produk Guess. Customer delight memoderasi pengaruh esteem needs terhadap niat beli konsumen pada produk Guess.

Berdasarkan kesimpulan di atas maka sara yang dapat diberikan adalah sebagai distributor produk Guess sedapat mungkin mempertahankan dan meningkatkan esteem needs yang dimiliki konsumen. Maka dari itu produsen Guess harus memperhatikan posisi dan pandangan konsumen akan bergunanya suatu produk Guess sehingga menjadi inspirasi dan meningkatkan esteem needs di kalangan masyarakat. Sebagai distributor pakaian Guess harus memperhatikan situasi Customer delight masyarakat, maka dari itu produsen Guess lebih meningkatan informasi mengenai kelebihan dari produk Guess sehingga konsumen merasa nyaman, percaya diri, tertarik dan benar-benar Guess sebagai produk yang dicari-cari dan dibutuhkan.

\section{REFERENSI}

Afwan Hariri A.P dan Putri Anindita A., 2014. Pengaruh Customer Delight terhadap Customer Loyalty pada Siswa LBPP-LIA Malang. Jurnal Ekonomi Bisnis. 14 (1): 70-79.

Alexander Preko, Samuel Kwami Agbanu, dan Mawuli Feglo. 2014. Service Delivery, Customer Satisfaction and Customer Delight in the Real Estate Business. Evidence from Elite Kingdom Investment and 
Consulting Company Ghana. European Journal of Business and Management. 6(3): 71-83.

Anand Kumar, Ricard W. Olshavsky. 2014. Exploring Alternative Antecedents of Customer Delight. International Journal of Cunsumer Satisfaction. 2(1): 14-26.

Baqiyatul Ukhwah. 2013. Pengaruh Customer Delight Terhadap Customer Loyalty Pada Alfamart Kenteng-Purworejo. Jurnal Ekonomi Bisnis. 2(3): 1-8.

Bayu Aji Narendra. 2013. Pengaruh Customer Delight (justice, esteem dan finishing touch) terhadap customer loyalty pada pengguna Blackberry. Jurnal Ekonomi Bisnis dan Kewirausahaan. 1(6): 1-10.

Deviana Wijoyo. 2014. Pengaruh Consumers Excitement, Cosumers Esteem dan Impulse Buying Behavior Intention terhadap Impulse Buying Behavior pada konsumen Hypermart Ciputra World Surabaya. Jurnal Ekonomi Bisnis dan Kewirausahaan. 1(2): 1-7.

Dhevika and Latasri. 2014. A Study on Customer Delight of Banks In Tiruchirappalli District. International Journal of Advanced Research in Management and Social Sciences. 3(6): 106-126.

Donald C. Barnes Joel E. Collier Stacey Robinson. 2014. Customer delight and work engagement. Journal of Services Marketing. 28(5): 380 - 390.

Donald C. Barnes, Nicole Ponder, and Kranti Dugar. 2015. Investigati ng the Key Routes to Customer Delight. Journal of Marketing Theory and Practice. 19(4): 359-375.

Gaurav Purohit and Divya Purohit. 2013. From Customer Satisfaction to Customer Delight: A New Trend in Hospitality Industry. Global Journal of Management and Business Studies. 3(5): 545-548.

Ghozali, Imam., 2011. Aplikasi Analisis Multivariat/2, Badan Penerbit Undip, Semarang.

Griffin, Jill., 2009. Customer Loyalty. Edisi Revisi, Jakarta : Erlangga.

Hera Anam and Dr. Rafia Faiz. 2016. An Empericcal Examination of Brand Loyalty Via Customer Delight In Pakistan. Journal of Management and Research. 3(1): 1-28. 
Cokorda Istri Agung Vera Nindia Putri, Peran Customer Delight Dalam...

Juliana dan Desrir. 2014. Pengaruh Tahapan Keputusan Pembelian terhadap Kepuasan Pelanggan pada Toko Terhubung (Online). Skripsi Fakultas Ekonomika dan Bisnis. Universitas Gadjah Mada.

Kenneth K. Kwong and Oliver H. M. Yau. 2012. The Conceptualization of Customer Delight:A Research Framework. Journal Asia Pacific Management Review. 7(2): 255-266.

Mabrur. M Ansori. 2014. Pengaruh Customer Delight terhadap Customer Loyalty pada Bank Syariah di Kota Semarang. Jurnal Ekonomi Bisnis dan Kewirausahaan. 1(1): 1-13.

Maggie Wenjing Liu Hean Tat Keh. 2015. Consumer delight and outrage: scale development and validation. Journal of Service Theory and Practice. 25(6): $680-699$.

Maria Luiza Souca. 2015. Customer dissatisfaction and delight: completely different concepts, or part of a satisfaction continuum. Journal of Management and Research. 9(1): 79-90.

Meilani Pandora, Ika Widyarini dan Ika Adita Silviandari. 2015. Pengaruh Price Discount Framing dan Need For Cognition Terhadap Intensi Membeli Produk Pakaian Wanita di Matahari Departement Store (Studi Pada Mahasiswi Fakultas Ilmu Sosial dan Ilmu Politik Universitas Brawijaya). Jurnal Ekonomi Bisnis. 1(4): 1-22.

Norma Komala Sari, Lili Adi Wibowo, Oce Ridwanudin. 2014. Upaya Menciptakan Customer Delight Melalui Service Excellence Hotel Santika Siligita Nusa Dua Bali (Survei terhadap Tamu SIP Member yang Menginap di Hotel Santika Siligita Nusa Dua Bali). Tourism and Hospitality Essentials (THE) Journal. 4(2): 789-792.

Richard L. Oliver, Roland T. Trust, Sajeebbarki. 2016. Customer Delight: Foundations, Findings, and Managerial Insight. Journal of Retailing. 73(3): 311-336.

Sandra Maria Correia Loureiro, Francisco J. Miranda, Michael Breazeale. 2013. The greater impact of value, trust and satisfaction in utilitarian, frequent-use retail. Journal of Service Management, 25(1): 101-124.

Sri Sudarsi. 2008. Customer Delight dan Loyalitas Pelanggan. Jurnal Fokus Ekonomi. 7(1): 44-51.

Sugiyono, 2013. Metode Penelitian Bisnis. Cetakan Ke-15. Penerbit Alfabeta. Bandung. 
E-Jurnal Manajemen Unud, Vol. 7, No. 2, 2018: 847-873

Suprihati, Wikan Budi Utami. 2015. Analisa Faktor -Faktor Yang Mempengaruhi Perilaku Konsumen Dalam Keputusan Pembelian Mobil Pribadi Di Kelurahan Gonilan Kabupaten Sukoharjo. Jurnal Paradigma. 13(1): 104-116.

Vidhya. K., C. Samudhra Rajkumar. 2013. Satisfaction to Delight - A Riview. Asia Pacific Journal of Marketing dan Management Review. 2(4): 1321. 